\title{
II. Ein Fall von Coniin-Vergiftung.
}

Mitgetheilt von Prof. Hugo Schulz.

Vergiftungen mit dem Alkaloid des Fleckschierlings, Conium maculatum, sind nicht gerade häufig, und dieser Umstand, sowie die eigenartigen Bedingungen, unter denen die gleich mitzutheilende Vergiftung zu. Stande kam, veranlassen mich zur Veroffentlichung derselben. 
In einer meiner Vorlesungen über Arzneimittellehre liess ich unter den Zuhörern ein Coniin enthaltendes Präparatenglas circuliren. Das Alkaloid selbst befand sich in einem engen Glasröhrchen, das, an der einen Seite mit einem Korkstöpsel verschlossen, in einem grösseren Präparatenglase untergebracht war. Im Laufe der Zeit hat sich durch den Kork hindurch soviel Conïn verflüchtigt, dass man beim Oeffnen des weiten Glases seinen specifschen Geruch deutlich erkennen kann. Ich hatte meinen Zuhörern Vorsicht beim Riechen an dem Präparate anempfohlen, es trat auch während der Dauer der Vorlesung kein besonderer Zufall ein. Am Tage darauf theilte mir einer der Herren mit, dass ein Comilitone sich, wie er glaube, Tags vorher durch das Riechen an dem Coniin vergiftet habe. Ich verfügte mich sofort in die Wohnung des Patienten, fand denselben im Bette vor und erfuhr Folgendes:

Herr X., 22 Jahre alt, kräftig und gesund, zur Zeit sein halbes Jahr mit der Waffe dienend, hatte am Tage vorher in der Vorlesung etwas lange an der Coniinflasche gerochen, weil er, wie er sagte, wegen eines leichten Schnupfens zuerst nicht deutlich habe riechen können. Nach der Vorlesung, um 5 Uhr Nachmittags, ging er in seine Wohnung, wobei ihm auffiel, dass er den Coniingeruch ständig noch verspürte. Allmählich überkam ihn eine mehr und mehr zunehmende Mattigkeit der Glieder, er konnte die Augen nicht auflialten, hatte das Gefühl von heftigem Brennen in der Conjunctiva und war schliesslich gezwungen, sich mit geschlossenen Augen auf das Sopha zu legen. Er empfand deutlich ein starkes Schwäche- und Müdigkeitsgefühl, namentlich in den Extremitätenmuskeln, das Sensorium war völlig frei, von geistiger Müdigkeit nichts vorhanden. Allmählich stellten sich heftige Kopfschmerzen ein, starkes Pulsiren in den Schläfen, der Genuss einer Tasse Thee änderte nichts. Herr X. wurde schliesslich gegen $7 \mathrm{Uhr}$ von einigen Bekannten vorgefunden, die ihn zu Bette brachten, da er selbst zu jeder Bewegung unfăhig war. Auch das Sprechen fiel ihm schwer, die Worte konnten nur langsam und schleppend ausgesprochen werden. Nachdem Herr X. zu Bette gebracht war, wurde ein schon vorher bemerktes Gefühl allgemeiner Hitze am ganzen Körper derartig stark, dass die Helfenden ein ausgesprochenes Fieber vor sich zu sehen glaubten. Nach einiger Zeit trat eine äusserst heftige Schweisssecretion ein, verbunden mit anhaltendem 'Thränenträufeln. Von Nachtruhe war nicht die Rede, es entwickelte sich starke Ideenflucht, Unfähigkeit, einen Gedanken zu fixiren, Bilder aus der Gegenwart und Vergangenheit eilten in wirrer Folge durcheinander. Am folgenden Morgen fühlte sich der Patient wesentlich leichter, die Kopfschmerzen bestanden allerdings noch fort, wie sie auch die Nacht hindurch angedauert hatten, waren aber deutlich schwåcher geworden. Herr $\mathrm{X}$. dachte daran, aufzustehen, dabei stellte sich aber heraus, dass auf jede, auch die geringste Bewegung, sofort ein grösserer, allgemeiner Schweisserguss erfolgte, was den Patienten veranlasste, zu Bette zu bleiben. Der geringfügige Schnupfen von Tags zuvor war verschwunden. Nachmittags um 5 Uhr sah ich den Patienten zuerst. Er lag noch im Bette, schilderte mir seine Erlebnisse der letzten 24 Stunden klar und deullich, klagte nur noch über die Kopfschmerzen und bot äusserlich keine Abnormität. Puls voll und weich, 88 in der Minute, Temperatur 37,6. Als Herr X. sich aus der liegenden Stellung aufrichtete und dann wieder hinlegte, brach der Schweiss wieder in verstärktem Maasse aus, die Haut des Kopfes, Rumpfes und der Extremitäten war völlig nass. Stuhlgang war im Laufe des Tages nicht erfolgt, Appetit nicht vorhanden, das sonst gefühlte Bedürfniss, zu rauchen, fehlte.

Die folgende Nacht war gut, und Herr X. erwachte Tags darauf ohne irgend welche Beschwerden zu fühlen, ging aus und verrichtete seine Obliegenheiten wie früher.

Es unterliegt, wenn wir den Verlauf der Erkrankung betrachten, keinem Zweifel, dass es sich handelte um eine Coniinvergiftung, hervorgerufen durch ein wenn auch nur kurz dauerndes Einathmen der Dämpfe des flüchtigen Alkaloids. Pöhlmann ${ }^{1}$ ) hat schon bei sich und Anderen anhaltende drückende Kopfschmerzen in der Supraorbitalgegend auftreten sehen bei Bereitung von Coniinlösungen zu Versuchszwecken, lediglich durch das Einathmen der dabei sich verflüchtigenden Dämpfe. Die Schüler Schroff's, die an sich mit innerer Aufnahme von Coniin experimentirten, empfanden selbst nach kleinen Dosen das Druckgefühl im Kopfe. Ferner berichtet Schroff ${ }^{2}$ ) bei der Schilderung der Versuchsergebnisse: "In allen Fällen wurde Feuchtwerden der Fingerspitzen, bei grossen Gaben selbst Nasswerden derselben und der Hände beobachtet", und weiter oben heisst es, dass die Experimentatoren nach der Aufnahme des Alkaloids unfähig wurden, zu denken und ihre Aufmerksamkeit auf bestimmte Gegenstände zu fixiren. Die von Herrn $\mathrm{X}$. beobachteten brennenden Schmerzen in den Augen dürfen wohl nicht auf eine direkte Anätzung der Conjunctiva durch die Coniindämpfe zurückgeführt werden, da sie erst nach Ablauf von mehr als einer Stunde sich entwickelten. Die wesentlichste Erscheinung, die allgemeine Muskellähmung, die die Augenlider wie auch die zur Sprachbildung nothwendigen Muskelgruppen nicht verschonte, ist bekanntlich typisch für die Wirkung des Schierlingsalkaloids und schon von Plato bei seinem Bericht vom Tode des Sokrates in ebenso charakteristischer wie lebendiger Darstellung geschildert."3)

1) Citirt bei Reil, Materia medica, 1857, p. 133.

2) Lehrbuch der Pharmakologie. 1873, p. 569.

3) Der von mir bearbeitete Artikel "Coniin" in Eulenburg's Encyclopädie enthält die bisher bekannten Fälle von Coniinvergiftungen ausführlich. 